\title{
1-(1-Propylsulfonic)-3-methylimidazolium chloride acidic ionic liquid catalyzed hydrolysis of cellulose in water: effect of metal ion co-catalysts
}

\author{
Bernard Wiredu and Ananda S. Amarasekara* \\ Department of Chemistry, Prairie View A\&M University, Prairie View, TX 77446, USA \\ e-mail: asamarasekara@pvamu.edu Tel: +1 936261 3107; fax: +1 9362613117
}

The effect of eight metal ions, $\mathrm{Cr}^{3+}, \mathrm{Mn}^{2+}, \mathrm{Fe}^{3+}, \mathrm{Co}^{2+} \mathrm{Ni}^{2+}, \mathrm{Cu}^{2+}, \mathrm{Zn}^{2+}$ and $\mathrm{La}^{3+}$ on 1-(1propylsulfonic)-3-methylimidazolium chloride acidic ionic liquid catalyzed hydrolysis of cellulose in water was studied at $140-170{ }^{\circ} \mathrm{C} . \mathrm{Mn}^{2+}, \mathrm{Fe}^{3+}$, and $\mathrm{Co}^{2+}$ as co-catalysts produced significant enhancements in total reducing sugar (TRS) yields, with $\mathrm{Mn}^{2+}$ showing the highest activity. $\mathrm{Mn}^{2+}$ as co-catalyst produced 91.8 , and $91.9 \%$ TRS yields, whereas samples without $\mathrm{Mn}^{2+}$ gave 28.0 and $28.7 \%$ yields at 160 and $170{ }^{\circ} \mathrm{C}$ respectively. The observed activation energies for cellulose hydrolysis without a co-catalyst and with $\mathrm{Mn}^{2+}$ co-catalyst are 78.1 \pm 1.4 and $32.8 \pm 4.9 \mathrm{~kJ} \cdot \mathrm{mol}^{-1}$ respectively.

KEYWORDS: cellulose, acidic ionic liquid, metal ions, total reducing sugars, glucose 


\section{Introduction}

Efficient and economical hydrolysis of cellulose and hemicellulose in lignocellulosic biomass to fermentable sugars is the major obstacle for the economical large scale production of cellulosic ethanol [1], [2]. This is due to a number of deficiencies in enzymatic saccharification technology employed in current operations. The main drawbacks are the need for energy consuming pretreatment and high enzyme cost coupled with the inability to recycle the enzyme preparation. Acid hydrolysis i.e., saccharification using dilute aqueous sulfuric acid at high temperature and pressure is an alternative technique, and in fact it was the method used in early cellulosic-ethanol plants in the 1940's, which was replaced by enzyme process developed in the last two decades. The main disadvantage of this dilute aqueous sulfuric acid hydrolysis of cellulosic biomass is the poor sugar yields, resulting in low ethanol yield and secondly the high energy cost associated with operating at temperatures above $250{ }^{\circ} \mathrm{C}$ at high pressures [3], [4]. Although the direct dilute aqueous acid saccharification gives relatively low sugar yields, quite a few research groups have taken an interest in recent times, taking a second look at this classical method [5]. This renewed interest may be due to its lower cost and simplicity, compared to enzymatic saccharification, which requires an additional pretreatment step [5]. Consequently, numerous approaches have been studied as improvements of the classical acid hydrolysis; and some of these modifications include the use of organic acids [6], solid acids and addition of co-catalysts [7], [8], [9] .

In recent years, few research groups have studied the effect of adding metal salts to aqueous acid pretreatment and acid catalyzed hydrolysis of cellulose [10], [11], as well as raw lignocellulosic biomass saccharifications [12], [13], [14]. In an earlier study, Monavari et al. reported a slight increase in glucose yields by the addition of catalytic amount of ferrous sulfate during the dilute acid pretreatment of softwoods [15]. The role of ferrous ion co-catalyst in enhancing dilute acid pretreatment of lignocellulosic biomass has been studied by FT-IR and microscopy methods as well [16]. Then in 2013, Zhao et al. investigated the role of $\mathrm{Mn}^{2+}, \mathrm{Fe}^{3+}, \mathrm{Cu}^{2+}$, and $\mathrm{Zn}^{2+}$ as a cocatalysts in the acid hydrolysis of corn stover under microwave radiation [17]. In this study they found that the four metal ion co-catalysts enhances the reducing sugar yields in the order $\mathrm{Fe}^{3+}>$ $\mathrm{Cu}^{2+}>\mathrm{Zn}^{2+}>\mathrm{Mn}^{2+}$, and the highest reducing sugar yield of $35.10 \%$ was obtained at a $3.0 \%$, concentration of ferrous sulfate as a co-catalyst [17]. In another recent study the effects of six metal ions: $\mathrm{Na}^{+}, \mathrm{K}^{+}, \mathrm{Mg}^{2+}, \mathrm{Ca}^{2+}, \mathrm{Cu}^{2+}$ and $\mathrm{Fe}^{3+}$ on hydrolysis of bamboo biomass by dilute 
hydrochloride acid in ionic liquid $n$-butylmethylimidazolium chloride was investigated [18]. In this study, Wang et al. reported a total reducing sugar yield of $67.1 \%$, using $\mathrm{CuCl}_{2}$ as the cocatalyst, after $4 \mathrm{~h}$ at $100{ }^{\circ} \mathrm{C}$. Furthermore, they noticed an increase in total reducing sugar yield by about $7 \%$ when the reaction time was decreased to $3 \mathrm{~h}[18]$.

Since 2009 we have been exploring the use of sulfonic acid group functionalized acidic ionic liquids [19], [20], [21] as well as alkyl/aryl sulfonic acids [6], [22] as catalysts for the hydrolysis of cellulose and lignocellulosic biomass for cellulosic ethanol process and other biofuel applications. Where we first reported that Brönsted acidic ionic liquid (BAIL) like 1-(1propylsulfonic)-3-methylimidazolium chloride can be used as an acid catalyst at temperatures below $100{ }^{\circ} \mathrm{C}$ and at atmospheric pressure for the hydrolysis of cellulose dissolved in the ionic liquid itself [19]. Later we found that these sulfuric acid derivatives with ionic liquid characteristics can be used as catalysts in aqueous phase as well [20]. For example, a dilute aqueous solution of acidic ionic liquid 1-(1-propylsulfonic)-3-methylimidazolium chloride was shown to be a better catalyst than aqueous sulfuric acid of the same $\mathrm{H}^{+}$ion concentration for the degradation of cellulose at moderate temperatures and pressures [20].

This enhanced catalytic activity of the 1-(1-propylsulfonic)-3-methylimidazolium chloride when compared to sulfuric acid can be explained as a result of an interaction or binding of the ionic liquid catalyst on the cellulose surface, which facilitates the approach of $-\mathrm{SO}_{3} \mathrm{H}$ group for the hydrolysis of the glycosidic link [23], [24]. This observation can be seen as an important lead for the development of an ionic liquid based catalyst for hydrolysis of cellulose. As recent studies of using metal ions and particularly transition metal ions are shown to enhance the mineral acid catalyzed cellulose hydrolysis, we hypothesized that even better catalytic effect enhancements can be expected for BAIL catalyzed cellulose hydrolysis. Therefore, in an attempt to test this hypothesis and to develop efficient acid catalyst system for cellulose ethanol process as well as an extension of our earlier work [19], [25], [21], [20], [26], we have studied the effect of metal ions as co-catalysts on 1-(1-propylsulfonic)-3-methylimidazolium chloride acidic ionic liquid catalyzed hydrolysis of cellulose in water as shown in figure 1 . 


\section{Experimental}

\subsection{Materials and Instrumentation}

Sigmacell cellulose - type 101 (DP $\sim 450$, from cotton linters), 1-methylimidazole, 1,3propanesultone, analytical grade chloride salts; $\mathrm{CrCl}_{3} \cdot 6 \mathrm{H}_{2} \mathrm{O}, \mathrm{MnCl}_{2} \cdot 4 \mathrm{H}_{2} \mathrm{O}, \mathrm{FeCl}_{3} \cdot 6 \mathrm{H}_{2} \mathrm{O}$, $\mathrm{CoCl}_{3} \cdot 6 \mathrm{H}_{2} \mathrm{O}, \mathrm{NiCl}_{2}, \mathrm{CuCl}_{2} \cdot 2 \mathrm{H}_{2} \mathrm{O}, \mathrm{ZnCl}_{2}$, and $\mathrm{LaCl}_{3}$ were purchased from Aldrich Chemical Co. Brönsted acidic ionic liquid catalyst was prepared by condensation of 1-methylimidazole with 1,3-propanesultone and acidification of the resulting salt with conc. $\mathrm{HCl}$ according to the literature procedure [27], [28]. Cellulose hydrolysis experiments were carried out in $25 \mathrm{~mL}$ stainless steel solvothermal reaction kettles with Teflon inner sleeves, purchased from Lonsino Medical Products Co. Ltd. Jingsu, China. These reaction kettles were heated in a preheated Precision Scientific model-28 laboratory oven with temperature accuracy $\pm 1{ }^{\circ} \mathrm{C}$. Total reducing sugars (TRS, total of glucose and glucose oligomers with reducing groups) produced during the hydrolysis was measured using 3,4-dinitrosalicylic acid (DNS) method [29]. The glucose produced in the hydrolysis was measured using glucose oxidase-peroxidase enzymatic assay [30]. The absorption readings in the DNS method and oxidase-peroxidase enzymatic assay were recorded using a Thermo Scientific GENESYS 10S UV/Vis spectrophotometer and $1.00 \mathrm{~cm}$ quartz cells.

\subsection{General experimental procedures for the degradation of cellulose samples using} aqueous 1-(1-propylsulfonic)-3-methylimidazolium chloride solutions with and without metal ions

A stock solution of the 1-(1-propylsulfonic)-3-methylimidazolium chloride acidic ionic liquid in water was prepared by dissolving appropriate amount of BAIL catalyst in deionized water to give an acid concentration of $0.0321 \mathrm{~mol} \mathrm{H}^{+} / \mathrm{L}$. The accuracy of the concentration was checked by titration with standardized aqueous $\mathrm{NaOH}$ solution using phenolphthalein as the indicator. Sigmacell cellulose-type 101 (DP 450) $(0.030 \mathrm{~g}, 0.185 \mathrm{mmol}$ of glucose unit of cellulose) was suspended in $2.00 \mathrm{~mL}$ of the aqueous acid solution and metal chloride $(20 \mathrm{~mol} \%$ of glucose equivalent in cellulose) was added to the stainless steel reaction kettle with a Teflon inner sleeve. The reaction kettle was firmly closed and heated in a thermostated oven maintained at the desired temperature for $3.0 \mathrm{~h}$. Then reaction kettle was removed from the oven and immediately 
cooled under running cold water to quench the reaction. The contents were transferred into a centrifuge tube and diluted to $10.0 \mathrm{~mL}$ with deionized water, neutralized by drop wise addition of $0.5 \mathrm{M}$ aq. $\mathrm{NaOH}$, and centrifuged at $1,700 \mathrm{~g}$ for $6 \mathrm{~min}$ to precipitate the solids. The clear supernatant was used for the total reducing sugar (TRS) determination by 3,4-dinitrosalicylic acid (DNS) method and the glucose formed was measured using glucose oxidase/peroxidase enzymatic assay as described in our earlier work [6]. A similar experiment without the metal salt was used as the reference. The TRS and glucose \% yields produced during the hydrolysis of Sigmacell cellulose (DP $\sim 450$ ) in aqueous BAIL solution at $140,150,160$ and $170{ }^{\circ} \mathrm{C}$, using $\mathrm{Cr}^{3+}, \mathrm{Mn}^{2+}, \mathrm{Fe}^{3+}, \mathrm{Co}^{2+} \mathrm{Ni}^{2+}, \mathrm{Cu}^{2+}, \mathrm{Zn}^{2+}$ and $\mathrm{La}^{3+}$ chlorides as co-catalysts, as well as the reference samples are shown in figures 2 and 3.

\section{Results and Discussion}

Imidazolium type sulfonic acid group functionalized BAIL 1-(1-alkylsulfonic)-3methylimidazolium chloride was chosen as the catalyst for cellulose hydrolysis study because our earlier studies have shown that this functionalized ionic liquid is a better catalyst than pyridinium and triethanol ammonium cation based acidic ionic liquids with built-in sulfonic acid groups for the cellulose hydrolysis [19]. In addition, our earlier studies have shown that 1-(1propylsulfonic)-3-methylimidazolium chloride is a better catalyst than sulfuric acid of the same acid strength for the degradation of cellulose to glucose and oligomers in dilute aqueous medium experiments [20]. In this study, the effect of adding eight metal chlorides as co-catalysts were compared as shown in figure 1. The total reducing sugar (TRS) yields produced during the hydrolysis of Sigmacell cellulose (DP 450) in aqueous BAIL solution at $140-170{ }^{\circ} \mathrm{C}$, using $\mathrm{Cr}^{3+}, \mathrm{Mn}^{2+}, \mathrm{Fe}^{3+}, \mathrm{Co}^{2+} \mathrm{Ni}^{2+}, \mathrm{Cu}^{2+}, \mathrm{Zn}^{2+}$ and $\mathrm{La}^{3+}$ chlorides as co catalysts is shown in figure 2. These results show that cellulose samples heated with $\mathrm{Mn}^{2+}, \mathrm{Fe}^{3+}, \mathrm{Co}^{2+}$ as co-catalysts produces significantly higher total reducing sugar yields compared to the sample heated in aqueous BAIL solution without the metal ions. The addition of $\mathrm{Ni}^{2+}, \mathrm{Cu}^{2+}, \mathrm{Zn}^{2+}$ and $\mathrm{La}^{3+}$ chlorides as cocatalysts failed to produce significant changes in TRS yields at all three temperatures; whereas the addition of $\mathrm{Cr}^{3+}$ caused a negative effect, resulting in a major reduction in TRS yield. The highest catalytic effect enhancement is observed in samples where $\mathrm{Mn}^{2+}$ is used as the cocatalyst. The cellulose samples hydrolyzed using BAIL with $\mathrm{Mn}^{2+}$ as co-catalyst produced TRS yields of $59.1,78.4,91.8$, and $91.9 \%$ at $140,150,160$, and $170{ }^{\circ} \mathrm{C}$ respectively; whereas 
cellulose hydrolyzed without $\mathrm{Mn}^{2+}$ produced TRS yields of $9.8,16.5,28.0$, and $28.7 \%$ at the same four temperatures. This is a 503, 375, 228, and $220 \%$ enhancements in TRS yield due to the addition of $\mathrm{Mn}^{2+}$ as co-catalyst to BAIL catalyzed cellulose hydrolysis at 140, 150, 160 and $170{ }^{\circ} \mathrm{C}$ respectively. We have checked the possibility of hydrolysis of metal chlorides to give $\mathrm{HCl}$ and cellulose hydrolysis due to any $\mathrm{HCl}$ formed. In this experiment we first measured the $\mathrm{pH}$ of $0.0321 \mathrm{~mol} \mathrm{H}^{+} / \mathrm{L}$ 1-(1-propylsulfonic)-3-methylimidazolium chloride acidic ionic liquid in water, which was 2.15 . Then metal chlorides were added separately to aliquots of ionic liquid solutions to give metal ion concentrations similar to the one used in the cellulose hydrolysis experiments. Measuring the $\mathrm{pH}$ of these solutions showed that there is no significant change in $\mathrm{pH}$ due to the addition of metal chloride salts. However, exchange between $\mathrm{H}^{+}$from acidic ionic liquid and metal ions from metal chloride cannot be ruled out in the solution.

The variation in glucose $\%$ yields due to the addition of metal ions as co-catalysts on BAIL catalyzed hydrolysis of cellulose in water is shown in figure 3 . This plot shows that addition of $\mathrm{Mn}^{2+}, \mathrm{Fe}^{3+}, \mathrm{Co}^{2+} \mathrm{Ni}^{2+}, \mathrm{Cu}^{2+}, \mathrm{Zn}^{2+}$ and $\mathrm{La}^{3+}$ chlorides as co-catalysts has no significant effect on glucose yields at all three temperatures. However the addition of $\mathrm{Cr}^{3+}$ caused a negative effect, resulting in a major reduction in glucose yield as in the case of TRS yield (figure 2). This outcome may be explained as a result of an adsorption of these metal ions on the cellulose surface in the heterogeneous system and promoting the BAIL catalyzed cleavage of the glycosidic bonds. On the other hand once the cellulose is partially depolymerized to water soluble oligomers these metal ions are no longer adsorbed on to the oligosaccharides in the homogeneous system, inactive as a co-catalyst, and this possibly will result glucose yields similar to the reference sample, as shown in figure 3. The low TRS and glucose yields in samples with $\mathrm{Cr}^{3+}$ ions may be due to oxidation of the depolymerized products by $\mathrm{Cr}^{3+}$. This conclusion was further supported by the fact that all $\mathrm{Cr}^{3+}$ added samples showed excessive charring after the $3 \mathrm{~h}$ reaction time. In addition, we are currently investigating the anomalous results of the $\mathrm{Cr}^{3+}$ added samples as a separate study under relatively lower temperatures and shorter reaction times.

The activation energies $\left(E_{a}\right)$ for aq. acidic ionic liquid catalyzed hydrolysis of cellulose with and without $\mathrm{Mn}^{2+}, \mathrm{Fe}^{3+}, \mathrm{Co}^{2+}, \mathrm{Ni}^{2+}, \mathrm{Cu}^{2+}, \mathrm{Zn}^{2+}$ and $\mathrm{La}^{3+}$ salts were calculated by using the first order rate constants at $140-160{ }^{\circ} \mathrm{C}$. The $\ln (\mathrm{k})$ vs. $1 / \mathrm{T}$ Arhenius plots gave good conformity with 
reasonable $\mathrm{R}^{2}$ values and observed activation energies are shown in table 1 . The $\mathrm{Cr}^{3+}$ co-catalyst experiment was not included in the $\mathrm{E}_{\mathrm{a}}$ calculation as this experiment gave exceptionally low TRS yields. The cellulose hydrolysis experiment using only aqueous 1-(1-propylsulfonic)-3methylimidazolium chloride acidic ionic liquid catalyst gave a $\mathrm{E}_{\mathrm{a}}$ of $78.1 \pm 1.4 \mathrm{~kJ}_{\mathrm{mol}}{ }^{-1}$ and this

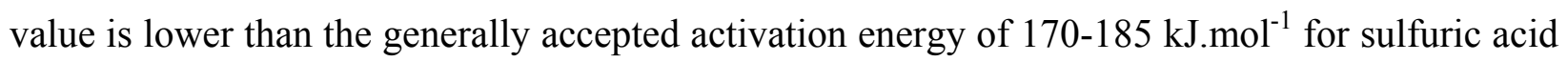
catalyzed hydrolysis of cellulose in water at high temperatures [31],[32]. This result further confirms our earlier finding that the acidic ionic liquid is a better catalyst than $\mathrm{H}_{2} \mathrm{SO}_{4}$ of equal $\left[\mathrm{H}^{+}\right]$in water [20]. The cellulose hydrolysis with three metal ions $\mathrm{Mn}^{2+}, \mathrm{Fe}^{3+}, \mathrm{Co}^{2+}$ which showed good co-catalyst activity with ionic liquid catalyst showed even lower activation energies $32.8 \pm 4.9,37.2 \pm 3.9$ and $44.2 \pm 10.4 \mathrm{~kJ} \mathrm{~mol}^{-1}$ respectively, as anticipated. The exact mechanism of the co-catalyst effect is not apparent from the available data, however some recent studies have proposed chelation of $\mathrm{Mn}^{2+}[33]$ and $\mathrm{Fe}^{3+}$ [34] with carbohydrates in hydrolysis and dehydration reactions. Therefore the high co-catalytic activity of $\mathrm{Mn}^{2+}, \mathrm{Fe}^{3+}, \mathrm{Co}^{2+}$ observed in this study may be also due to a similar interaction or binding of the BAIL-metal ion catalyst to cellulose surface, disrupting the cellulose H-bonding network. The highest TRS yield enhancement by a metal ion co-catalyst in the preceding study is $17.6 \%$ with $0.23 \%(\mathrm{w} / \mathrm{w}) \mathrm{HCl}$ as the catalyst and $0.13 \%(\mathrm{w} / \mathrm{w}) \mathrm{Cu}^{2+}$ ions as the co-catalyst [18]. Therefore, as far as we are aware the present result of $503 \%$ TRS yield enhancement at $140{ }^{\circ} \mathrm{C}$, by the addition of $\mathrm{Mn}^{2+}$ as co-catalyst to BAIL catalyst represent the highest TRS yield enhancement in an acid catalyzed hydrolysis of cellulose. The present study shows that $\mathrm{Mn}^{2+}, \mathrm{Fe}^{3+}$ and $\mathrm{Co}^{2+}$ as co-catalysts can produce unprecedented enhancements in cellulose hydrolysis during the BAIL catalyzed hydrolysis of cellulose in water, but very small or no effect on glucose yields. Glucose-oligomers and glucose produced in these experiments could be recovered by ion exclusion type separation methods as described by Mai and co corkers [35]. We are working on the product separation as a continuation of this work.

\section{Conclusion}

In the series of metal chlorides studied, $\mathrm{Mn}^{2+}, \mathrm{Fe}^{3+}, \mathrm{Co}^{2+}$ produced exceptional enhancements in total reducing sugar yields during the BAIL catalyzed hydrolysis of cellulose. On the other hand none of the metal ions showed significant effect on glucose yield, except in the case $\mathrm{Cr}^{3+}$, which showed a reduction in reducing sugar and glucose yields, most likely due to a different 
mechanism. Among the metal ions studied, $\mathrm{Mn}^{2+}$ showed the highest activity as a co-catalyst. The combination of $\mathrm{Mn}^{2+}$ with BAIL can be used as a lead for the development of a chemical catalyst system for the efficient depolymerization of cellulosic biomass, with potential applications in the cellulosic-ethanol process.

\section{Acknowledgments}

We thank National Science Foundation grants CBET-0929970, CBET-1336469, HRD-1036593, and United States Department of Agriculture grant CBG-2010-38821-21569 for financial support. 


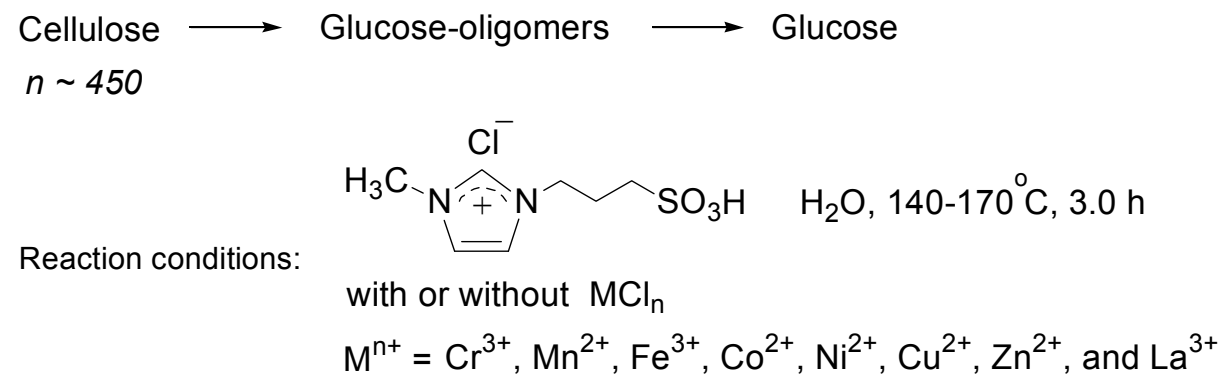

Fig. 1. 


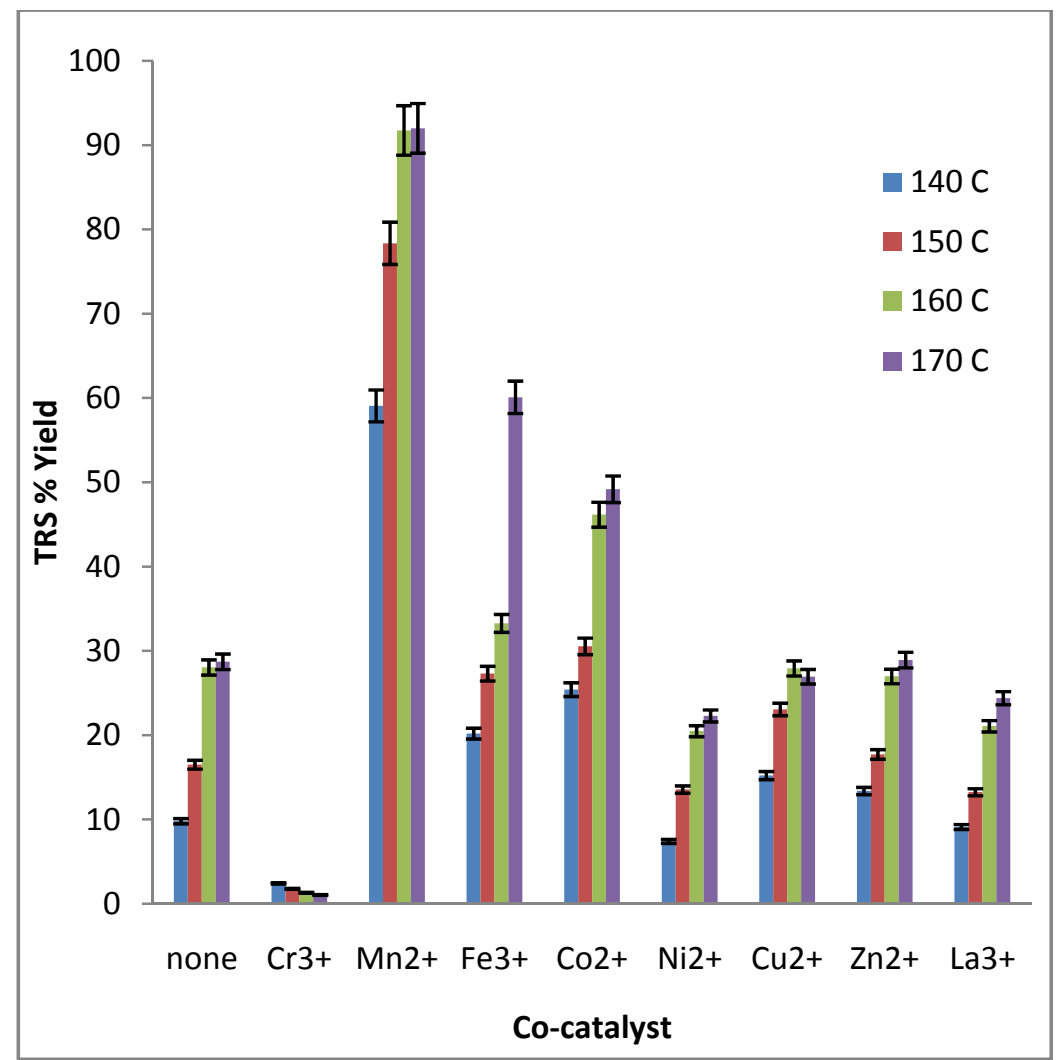

Fig. 2. 


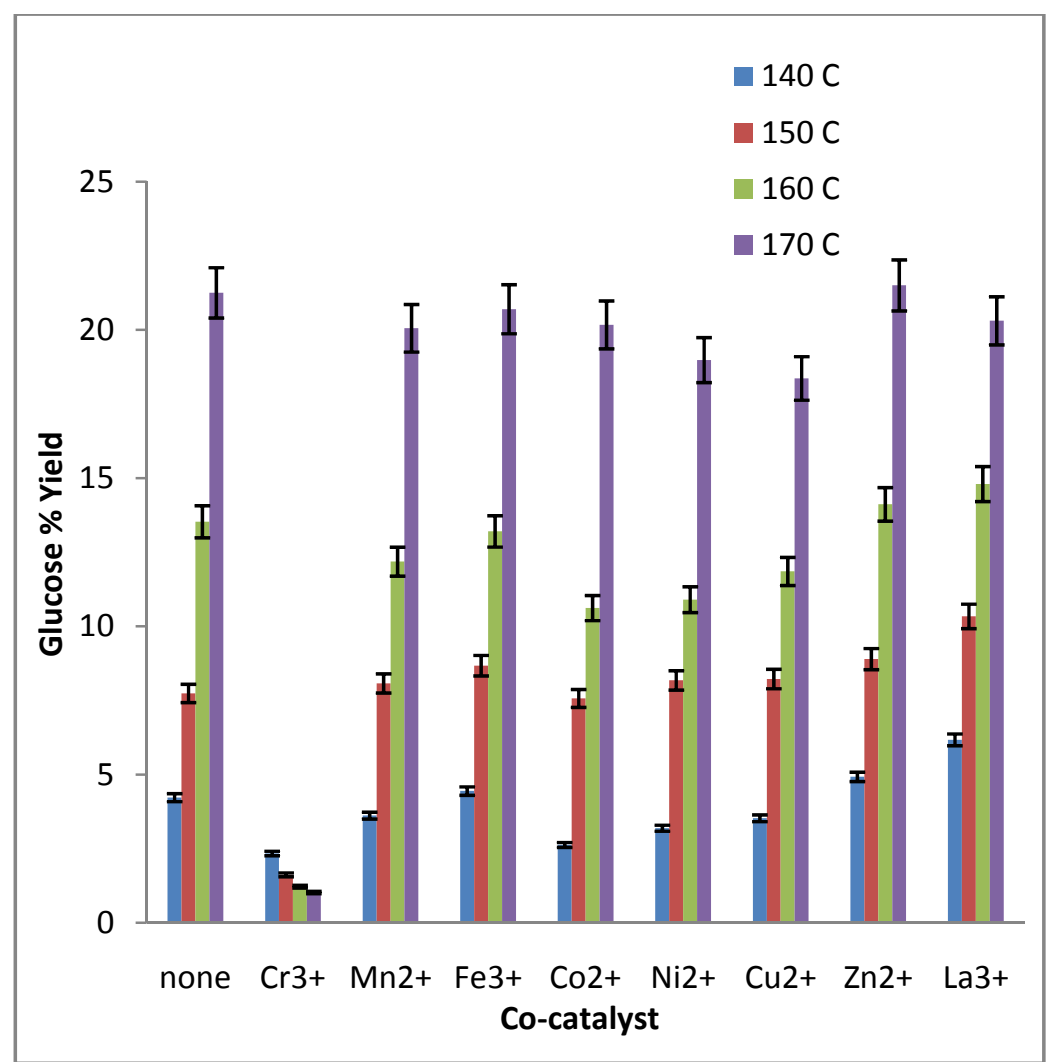

Fig. 3. 
Table 1

\begin{tabular}{|c|c|c|c|}
\hline $\begin{array}{c}\text { Metal ion } \\
\text { co-catalyst }\end{array}$ & $\boldsymbol{E}_{\boldsymbol{a}}\left(\boldsymbol{k J . m o} \boldsymbol{I}^{\mathbf{1}}\right)$ & $\left.\boldsymbol{A} \boldsymbol{( h}^{-\mathbf{1}}\right)$ & $\boldsymbol{R}^{\mathbf{2}}$ \\
\hline none & $78.1 \pm 1.4$ & $2.5 \times 10^{8} \pm 1.5$ & 0.9997 \\
\hline $\mathrm{Mn}^{2+}$ & $32.8 \pm 4.9$ & $2.8 \times 10^{3} \pm 4.0$ & 0.9781 \\
\hline $\mathrm{Fe}^{3+}$ & $37.2 \pm 3.9$ & $3.4 \times 10^{3} \pm 3.1$ & 0.9887 \\
\hline $\mathrm{Co}^{2+}$ & $44.2 \pm 10.4$ & $3.2 \times 10^{3} \pm 19$ & 0.9475 \\
\hline $\mathrm{Ni}^{2+}$ & $75.7 \pm 7.2$ & $9.5 \times 10^{7} \pm 7.9$ & 0.9909 \\
\hline $\mathrm{Cu}^{2+}$ & $47.9 \pm 6.7$ & $5.9 \times 10^{4} \pm 8.4$ & 0.9762 \\
\hline $\mathrm{Zn}^{2+}$ & $52.0 \pm 6.7$ & $1.6 \times 10^{5} \pm 6.7$ & 0.9836 \\
\hline
\end{tabular}




\section{$\underline{\text { Figure captions }}$}

Fig. 1. Hydrolysis of Sigmacell cellulose (DP $\sim 450)$ in aqueous 1-(1-propylsulfonic)-3methylimidazolium chloride acidic ionic liquid at $140-170{ }^{\circ} \mathrm{C}$, with or without $\mathrm{Cr}^{3+}, \mathrm{Mn}^{2+}, \mathrm{Fe}^{3+}$, $\mathrm{Co}^{2+} \mathrm{Ni}^{2+}, \mathrm{Cu}^{2+}, \mathrm{Zn}^{2+}$ and $\mathrm{La}^{3+}$ chlorides as co-catalysts

Fig. 2. The total reducing sugar (TRS) \% yields produced during the hydrolysis of Sigmacell cellulose (DP $\sim 450)$ in aqueous 1-(1-propylsulfonic)-3-methylimidazolium chloride acidic ionic liquid at $140,150,160$ and $170{ }^{\circ} \mathrm{C}$, using $\mathrm{Cr}^{3+}, \mathrm{Mn}^{2+}, \mathrm{Fe}^{3+}, \mathrm{Co}^{2+}, \mathrm{Ni}^{2+}, \mathrm{Cu}^{2+}, \mathrm{Zn}^{2+}$ and $\mathrm{La}^{3+}$ chlorides as co-catalysts.

$0.030 \mathrm{~g}$ of Sigmacell cellulose in $2.00 \mathrm{~mL}$ of aq. 1-(1-propylsulfonic)-3-methylimidazolium $(0.0321 \mathrm{~mol} \mathrm{H} / \mathrm{L}),\left[\mathrm{M}^{\mathrm{n}+}\right]=20 \mathrm{~mol} \%$ of glucose equivalent in cellulose and reaction time $3.0 \mathrm{~h}$ were used in all experiments. Averages of duplicate experiments

Fig. 3. The glucose \% yields produced during the hydrolysis of Sigmacell cellulose (DP $~ 450)$ in aqueous 1-(1-propylsulfonic)-3-methylimidazolium chloride acidic ionic liquid at 140, 150, 160 and $170{ }^{\circ} \mathrm{C}$, using $\mathrm{Cr}^{3+}, \mathrm{Mn}^{2+}, \mathrm{Fe}^{3+}, \mathrm{Co}^{2+}, \mathrm{Ni}^{2+}, \mathrm{Cu}^{2+}, \mathrm{Zn}^{2+}$ and $\mathrm{La}^{3+}$ chlorides as co-catalysts. $0.030 \mathrm{~g}$ of Sigmacell cellulose in $2.00 \mathrm{~mL}$ of aq. 1-(1-propylsulfonic)-3-methylimidazolium $\left(0.0321 \mathrm{~mol} \mathrm{H}^{+} / \mathrm{L}\right),\left[\mathrm{M}^{\mathrm{n}+}\right]=20 \mathrm{~mol} \%$ of glucose equivalent in cellulose and reaction time $3.0 \mathrm{~h}$ were used in all experiments. Averages of duplicate experiments

Table 1. Activation energy $\mathrm{E}_{\mathrm{a}}\left(\mathrm{kJ} \cdot \mathrm{mol}^{-1}\right)$ and pre-exponential factor $\mathrm{A}\left(\mathrm{h}^{-1}\right)$ for hydrolysis of Sigmacell cellulose (DP 450) in aqueous 1-(1-propylsulfonic)-3-methylimidazolium chloride acidic ionic liquid at in $140-160{ }^{\circ} \mathrm{C}$, temperature range, with and without $\mathrm{Mn}^{2+}, \mathrm{Fe}^{3+}, \mathrm{Co}^{2+}, \mathrm{Ni}^{2+}$, $\mathrm{Cu}^{2+}, \mathrm{Zn}^{2+}$ and $\mathrm{La}^{3+}$ chlorides as co-catalysts. 


\section{References}

[1] A.S. Amarasekara, Handbook of Cellulosic Ethanol, John Wiley \& Sons 2013.

[2] T.H. Kim, T.H. Kim, Overview of technical barriers and implementation of cellulosic ethanol in the U.S, Energy, 66 (2014) 13-19.

[3] P. Lenihan, A. Orozco, E. O'Neill, M.N.M. Ahmad, D.W. Rooney, G.M. Walker, Dilute acid hydrolysis of lignocellulosic biomass, Chem. Eng., J. 156 (2010) 395-403.

[4] T.R. Brown, R.C. Brown, A review of cellulosic biofuel commercial-scale projects in the United States, Biofuels, Bioproduct. Biorefining, 7 (2013) 235-245.

[5] R. Chen, S. Zhu, C. Chen, B. Cheng, J. Chen, Y. Wu, Reviving the Acid Hydrolysis Process of Lignocellulosic Material in Biorefinery, BioResources, 9 (2014) 1824-1827.

[6] A.S. Amarasekara, B. Wiredu, Aryl sulfonic acid catalyzed hydrolysis of cellulose in water, App. Catal. A: Gen., 417-418 (2012) 259-262.

[7] Y.-B. Huang, Y. Fu, Hydrolysis of cellulose to glucose by solid acid catalysts, Green Chem., 15 (2013) 1095-1111.

[8] L. Vilcocq, P.C. Castilho, F. Carvalheiro, L.C. Duarte, Hydrolysis of Oligosaccharides Over Solid Acid Catalysts: A Review, ChemSusChem, 7 (2014) 1010-1019.

[9] J. Li, H. Xiu, M. Zhang, H. Wang, Y. Ren, Y. Ji, Enhancement of cellulose acid hydrolysis selectivity using metal ion catalysts, Current Org. Chem., 17 (2013) 1617-1623.

[10] S. Dutta, S. De, M.I. Alam, M.M. Abu-Omar, B. Saha, Direct conversion of cellulose and lignocellulosic biomass into chemicals and biofuel with metal chloride catalysts, J. Catal., 288 (2012) 8-15.

[11] L. Peng, L. Lin, J. Zhang, J. Zhuang, B. Zhang, Y. Gong, Catalytic conversion of cellulose to levulinic acid by metal chlorides, Molecules, 15 (2010) 5258-5272.

[12] L. Liu, J. Sun, C. Cai, S. Wang, H. Pei, J. Zhang, Corn stover pretreatment by inorganic salts and its effects on hemicellulose and cellulose degradation, Bioresource Technol., 100 (2009) 5865-5871.

[13] S.R. Kamireddy, J. Li, M. Tucker, J. Degenstein, Y. Ji, Effects and mechanism of metal chloride salts on pretreatment and enzymatic digestibility of corn stover, Ind. Eng. Chem. Res., 52 (2013) 1775-1782.

[14] B. Wiredu, A.S. Amarasekara, The effect of metal ions as co-catalysts on acidic ionic liquid catalyzed single-step saccharification of corn stover in water, Bioresource Technol., 189 (2015) 405-408. 
[15] S. Monavari, M. Galbe, G. Zacchi, The influence of ferrous sulfate utilization on the sugar yields from dilute-acid pretreatment of softwood for bioethanol production, Bioresource Technol., 102 (2011) 1103-1108.

[16] H. Wei, B.S. Donohoe, T.B. Vinzant, P.N. Ciesielski, W. Wang, L.M. Gedvilas, Y. Zeng, D.K. Johnson, S.-Y. Ding, M.E. Himmel, Elucidating the role of ferrous ion co-catalyst in enhancing dilute acid pretreatment of lignocellulosic biomass, Biotechnol. biofuel., 4 (2011) 48.

[17] S. Zhao, P. Li, Q. Zhang, J. Zhang, L. Kong, Production of reducing sugar from corn stover by dilute acid hydrolysis co-catalyzed with metal salts under microwave radiation, Res. Chem. Intermediate., 39 (2013) 3803-3812.

[18] N. Wang, J. Zhang, H. Wang, Q. Li, S.a. Wei, D. Wang, Effects of metal ions on the hydrolysis of bamboo biomass in 1-butyl-3-methylimidazolium chloride with dilute acid as catalyst, Bioresource Technol., 173 (2014) 399-405.

[19] A.S. Amarasekara, O.S. Owereh, Hydrolysis and decomposition of cellulose in bron̈sted acidic ionic liquids under mild conditions, Ind. Eng. Chem. Res., 48 (2009) 10152-10155.

[20] A.S. Amarasekara, B. Wiredu, Degradation of cellulose in dilute aqueous solutions of acidic ionic liquid 1-(1-propylsulfonic)-3-methylimidazolium chloride, and p-toluenesulfonic acid at moderate temperatures and pressures, Ind. Eng. Chem. Res., 50 (2011) 12276-12280.

[21] A.S. Amarasekara, P. Shanbhag, Degradation of Untreated Switchgrass Biomass into Reducing Sugars in 1-(Alkylsulfonic)-3-Methylimidazolium Brönsted Acidic Ionic Liquid Medium Under Mild Conditions, Bioenerg. Res., 6 (2013) 719-724.

[22] A.S. Amarasekara, B. Wiredu, A comparison of dilute aqueous p-toluenesulfonic and sulfuric acid pretreatments and saccharification of corn stover at moderate temperatures and pressures, Bioresource Technol., 125 (2012) 114-118.

[23] E.S.R.E. Hassan, F. Mutelet, M. Bouroukba, Experimental and theoretical study of carbohydrate-ionic liquid interactions, Carbohyd. Polym., 127 (2015) 316-324.

[24] Y. Zhang, A. Xu, B. Lu, Z. Li, J. Wang, Dissolution of cellulose in 1-allyl-3methylimizodalium carboxylates at room temperature: A structure-property relationship study, Carbohyd. Polym., 117 (2015) 666-672.

[25] A.S. Amarasekara, O.S. Owereh, Synthesis of a sulfonic acid functionalized acidic ionic liquid modified silica catalyst and applications in the hydrolysis of cellulose, Catal. Commun., 11 (2010) 1072-1075.

[26] A.S. Amarasekara, B. Wiredu, Br\&\#246;nsted Acidic Ionic Liquid 1-(1-Propylsulfonic)-3methylimidazolium-Chloride Catalyzed Hydrolysisof D-Cellobiose in Aqueous Medium, Int. J. Carbohyd. Chem., 2012 (2012) 6. 
[27] J. Gui, X. Cong, D. Liu, X. Zhang, Z. Hu, Z. Sun, Novel Brønsted acidic ionic liquid as efficient and reusable catalyst system for esterification, Catal. Commun., 5 (2004) 473-477.

[28] Q. Yang, Z. Wei, H. Xing, Q. Ren, Brönsted acidic ionic liquids as novel catalysts for the hydrolyzation of soybean isoflavone glycosides, Catal. Commun., 9 (2008) 1307-1311.

[29] C. Breuil, J.N. Saddler, Comparison of the 3,5-dinitrosalicylic acid and Nelson-Somogyi methods of assaying for reducing sugars and determining cellulase activity, Enzyme Microbial Technol., 7 (1985) 327-332.

[30] H.U. Bergmeyer, Bernt, E., Methods of Enzymatic Analysis, in: H.U. Bergmeyer (Ed.), Academic Press, NewYork, 1974, pp. pp 1205-1212.

[31] L. Shuai, X. Pan, Hydrolysis of cellulose by cellulase-mimetic solid catalyst, Energy Environ. Sci., 5 (2012) 6889-6894.

[32] L.V.A. Gurgel, K. Marabezi, M.D. Zanbom, A.A.D.S. Curvelo, Dilute acid hydrolysis of sugar cane bagasse at high temperatures: A Kinetic study of cellulose saccharification and glucose decomposition. Part I: Sulfuric acid as the catalyst, Ind. Eng. Chem. Res., 51 (2012) 1173-1185.

[33] F. Tao, H. Song, J. Yang, L. Chou, Catalytic hydrolysis of cellulose into furans in MnCl2ionic liquid system, Carbohyd. Polym., 85 (2011) 363-368.

[34] X. Kästele, C. Sturm, P. Klüfers, 13C NMR spectroscopy as a tool for the in situ characterisation of iron-supplementing preparations, Europ. J. Pharmaceutic. Biopharmaceutic., 86 (2014) 469-477.

[35] N.L. Mai, N.T. Nguyen, J.-I. Kim, H.-M. Park, S.-K. Lee, Y.-M. Koo, Recovery of ionic liquid and sugars from hydrolyzed biomass using ion exclusion simulated moving bed chromatography, J. Chromatography A, 1227 (2012) 67-72. 